\title{
A Study of the Causes of Price Fluctuation in Apple Commodity and Consumer Shopping Behavior Based on Taste, Preferences, and Will- ingness to Pay
}

\author{
Shiyuan Huang*, Rubal Mistry \\ Cornell University, ITHACA 14850, USA. E-mail: Shiyuauh518@163.com
}

\begin{abstract}
The profit margin on the retailer's side is thin, so increasing the consumer's willingness to pay is crucial for the supply side to earn more profit. In this paper, the authors develop a taste test to see if consumers' preference for organic and local apples can alter their taste perception for the same apple. The result showed consumer's preference does change his/her taste preference on the same apple. Besides the experiment, the authors also design a survey to know the consumer's shopping preferences and the exact willingness to pay. The survey results show that consumers are in support of Local Apples as compared to Organic Apples but are willing to pay more for Organic Apples than Local Apples. Another conclusion that can be drawn is that this survey indicates that there is a huge profit margin for retailers as consumers are willing to pay more for organic apples than the average market price for the apples.
\end{abstract}

Keywords: Price Fluctuation; Apple Commodity; Willingness to Pay

\section{Literature review}

Fresh fruit is essential in people’s everyday life. Apple, as government support promoting the program, helps brand the nutrition benefit of apple, has become the most popular fruit in the United States. As a result, the price fluctuation of apple has a significant impact on the retailer's side, because they will lose money because of the input cost increase. We need to know why apple prices fluctuate and how retailers earn a profit when changes occur. The following review of articles helps illustrate what the key factors affect apple retail price and how different quality attributes can affect people's purchase decisions and willingness to pay.

Price fluctuation on agriculture products is crucial for the supply side to manage their company. Due to the nature of agriculture commodities, suppliers are unable to react quickly to the changes. As a result, it is essential for the supplier, especially the retailers, to understand what factors cause the price fluctuation, to prepare and adjust the price for the new changes, and earn the profit. Freebairn(1984) ${ }^{[1]}$ studies different patterns of fixed retail and farm prices for meat, fresh produce and eggs, and cereal products during the 1970s using monthly price data. Freebairn analyzes those datasets to understand how to farm food prices and non-farm input costs, and the amount of substitute products changes the retail food price. He set up a markup model in which the retail price is regressed on the current and lagged farm food price, wage rate, and a substitute product retail price. After reverting the model, the result shows that wages have a significant impact on the retail price. The increase in farm price does increase the retail price, but the elasticity of retail price concerning the farm price is between 0.4 and 0.6. Freebairn also states that the price change in the substitutes has a counter-effect on the price of retail products.

Copyright (C) 2020 Shiyuan Huang et al.

doi: 10.18282/ff.v9i4.1538

This is an open-access article distributed under the terms of the Creative Commons Attribution Non-Commercial License

(http://creativecommons.org/licenses/by-nc/4.0/), which permits unrestricted non-commercial use, distribution, and reproduction in any medium, provided the original work is properly cited. 
Besides wages and farm prices, Thompson and Lyon $(1989)^{[2]}$ found that government policy has an impact on the retail price. They examine how marketing order impacts the farm-retail spread by comparing the price spread on California-Arizona navel oranges with the policy and the price spread without the policy. The article shows that the price spread decreased when there is a suspension of marketing order, and the retail price is very responsive to policy changes. The authors implied that the quantity control could set the price on a level higher than the equilibrium level and help the retailers to exploit the market power and gain stable profit. Because of nature's fresh produce, seasonality is another critical influencer that affects the price. According to Plattner, Perez, and Thornsbury(2014) ${ }^{[3]}$, most fresh fruit has a distinct seasonal pattern of price. However, when they examine the seasonal patterns of apple price, the result shows that unlike another fresh produce price, the seasonal price fluctuation in the apple industry has been mitigating since the 1980s. New varieties with later harvest seasons and more advanced storage technology help extend the marketing season. The increased international demand and growing market for processing apples also help to absorb the excess domestic supply. As a result, apples present a weak seasonal price pattern. This article helps to rule out one determination for the factors that affect apple's price.

Weather is another crucial factor that affects apple's price. Hami and Pantziarides(2011) conclude in his news report that fruit prices increased significantly after bad weather. However, the supplier has ways to deal with the weather risk and keep earning a profit when disaster comes. Ho, Ifft, Rickard, and Turvey(2018) ${ }^{[4]}$ examines how farm cops with weather risk in different ways. They study three main strategies used most by producers. The first one is a high tunnel, unheated greenhouses that provide a protected environment for fruit. The rest is revenue-based crop insurance and weather insurance. The article finds that the high tunnel yield high expected return compares to the rest of the strategies.

Besides the weather, according to Volpe, Roeger, and Leibtag $(2013)^{[5]}$, transportation cost is another factor affecting the fresh produce price. They examine how transportation cost affects the fresh fruit and vegetable price. The fuel price is transmitted to the wholesale produce price through transportation cost, which increases the cost of a retail store. Fuel price affects fresh produce in many ways, including the distance between retail store and origin of the produce, methods of transportation including track or flight, and commodity-specific factors like perishability and storability. Richard(2014) ${ }^{[6]}$ agrees on Volpe, Roeger, and Leibtag $(2013)^{[5]} \mathrm{s}$ opinions. He states the fresh produce price is the most volatile in the retail food price. One of the reasons for the price volatility is that the oil price is frequently changed. Most fresh produce travels a long distance to get into consumer's hands, so the transportation cost consists of an important component in the retail fresh produce price. Richard found that prices of fresh produce grown in the United States, Canada, and Mexico are affected more by the oil price fluctuation, compared to those of fresh produce grown in South and Central America. The reason is that produce grown in the United States, Canada, and Mexico are transported by a track which is the high fuel cost per pound.

After examining the factors that could change Apple's price, the focus of this research shifts to how retailers earn a profit when they experience price fluctuation by changing consumer's willingness to pay. Karipidis and Galanopou$\operatorname{los}(2000)^{[7]}$ examine whether consumer-define factors, such as product quality, place of product origin, and the time of availability - whether the fruit is in season or not - affect apple price and the market value for different apples. The result showed that apple quality, which includes organic label, Non-GMO label, is a significant factor impacting the purchasing decision. The apple's origin also affects consumer decisions because consumer trends add value to apples from specific regions. There is no evidence that people would pay attention to the availability of apples. The article implies that the supply-side could exploit the profit opportunity by understanding the price premium of consumers' willingness to pay for a different Apple product. Khan, Shah, Saddozai, Fayaz, Jan, and Ali (2019) ${ }^{[8]}$ agree on Karipidis and Galanopoulos's (2000) ${ }^{[7]}$ findings and provide more evidence. They investigate consumer's preferences and estimate consumer's willingness to pay for different attributes for the apple. They state that consumers choose this specific apple because of its responses to consumer's preference for various quality attributes, which can be characterized as external appearances, such as size, shape, color, and internal factors, such as aroma and taste. Nutrition value is another critical factor that influences consumer's purchase behavior. The article concludes that consumers have strong preferences for apples’ different quality attributes, and their willingness to pay is different for different traits. 
After knowing the consumers' willingness to pay can be changed by different quality attributes, the researchers want to learn how specific characteristics change the consumers' perchance decisions. Weibel and Konopacka(2012) ${ }^{[9]}$ aim their goal in an organic direction. They conduct this study in Poland and Switzerland to examine people's acceptance of organic apple and conventional apple. They conduct a taste experiment with additional questionnaires to ask people to rate their appearance and tasting quality. The first run is a blind test and on the second run, the samples were labeled as organic and conventional and their prices were shown. The result shows people tend to rate appearance and tasting quality higher when they see the label. This article indicates that people tend to perceive higher quality when apple's attribute response to their preference and consumers perceive higher quality when the price is higher, which leaves retailers an opportunity to earn the profit. While Bernard, and Liu (2017) ${ }^{[10]}$ are in the same direction as Weibel and Konopacka(2012 $)^{[9]}$, they take a slightly different path to understanding how people's perceptions change their purchase decisions. According to Khan, Shah, Saddozai, Fayaz, Jan, and Ali (2019) ${ }^{[12]}$, taste is an important internal characteristic that influences peoples' purchase decisions and willingness to pay. Bernard and Liu (2017) ${ }^{[10]}$ examine whether people's beliefs in apple can change their taste of apple. They conduct a taste experiment and a survey to find out people's opinions on organic and local food. The result shows that people who think organic and local food tastes better and good for their health. People's beliefs on certain quality attributes can change their perception of taste. Jo and Lusk's (2018) ${ }^{[11]}$ 's research share a similar opinion with the above articles. They study the effect of the nutrition label on price and taste expectations. They elicit beliefs of price, taste, and health of 60 foods in three countries and study how the healthy attribute label changes people's intention to buy and premiums they are willing to pay. The article shows the result that health and taste perceptions respond more to positive health information, but price perceptions respond more to negative healthy information. There is also a positive relationship between health and taste. Wolfe et al $(2018)^{[12]}$ are on the same direction with the above authors. They study how different labels could affect consumer's willingness to pay. They conduct a taste test for edamame, followed by an auction, and finally a survey to determine consumer's willingness to pay for genetically modified labeled edamame and non genetically modified labeled edamame. The result shows that there is a significant price premium to pay for the non-GM edamame but the overall taste impression did not differ between GM and non-GM edamame. The result indicates that people would pay a higher price for the label even though the taste is not different.

The structure of the taste experiment and the statistical model used in the experiment is developed from the model Bernard \& $\operatorname{Liu}(2017)^{[10]}$ used in their paper. The structure of the experiment is similar to theirs but this paper's experiment is simpler compared to them. The data analysis used in the taste experiment follows the steps on Bernard\&Liu(2017) ${ }^{[10]}$, paper to get a reasonable and unbiased result.

Apple is considering staple food in our plates, so study price fluctuation is important for retailers to keep earning profit. Even though the above literature provides helpful information and helps build the experiment model's for this research, further research is needed to understand how retailers exploit the profiting opportunities by altering consumer's willingness to pay and what factors impact the price affect the retailers' profit most.

Taste and Rating Experiment

\section{Experimental design and preparation}

\subsection{Experiment preparation}

Participants were expected to have more knowledge of local and organic food, current food trends, and be more sensitive to the organic label. This group of participants was able to represent the younger consumer in the market. The location was in the community public area on the researcher's own home. Participants from this location were able to provide a more diversified sample to the experiment. Participants were from different age groups, educational backgrounds, and income levels. Some of them were sensitive to the added nutrition value of organic or local food and willing to pay the premium for organic and local food. However, some of them are not familiar with the local and local concept or know, but their income level did not allow them to pay for the premiums. 


\subsection{Experiment design}

The gala apple was chosen for the experiment because it is a common and familiar apple variety. Apples that were purchased for experimental use had to have identical appearance, skin texture to avoid participants judging the taste based on appearance because people have a bias if apple's external attributes do not correspond with their preference(Khan, Shah, Saddozai, Fayaz, Jan and Ali, $2019^{[8]}$ ). There were five slices of apple prepared on one plate. These slices were called slice A, slice B, slice C, slice organic. Slice A and slice organic are from the same organic apple. The only difference was that slice A had no organic label to indicate its organic. The slice B and slice local were also from the same local apple.

The experiment has no monetary incentive, so the participants were voluntary to conduct the experiment. After participants agreed to do the experiment, a plate of five slices of apple will be served to participants, with a taste rating form. The rating ranges from 1 to 5.1 indicates terrible taste and 5 indicates very delicious. After the tasting test, the participants were asked to survey their opinion on local and organic food. Participants were asked to rate their agreeableness on those statements. The rating scale was ranged from 1 to 5,1 as strongly disagree and 5 as strongly agree. At last, the participants got another survey to fill out their races, household income level, education level, age, and sex.

\subsection{Summary on the participants' background}

This experiment uses the Big Mac Index to convert the household income from yuan to dollars rather than use the real exchange rate between dollars and yuan.

\section{Data analysis and result}

\subsection{Opinion toward statements}

Participants had positive opinions on organic and local food, with a mean of 4.13 and 4.15. The result corresponds with the participant's reaction to the statement that organic food and local food can benefit your health. Participants' opinion toward organic food and local food is healthier for their body. The mean of the statement that organic food is healthier is 4.33. It is a bit higher than the mean of people's opinion that local food can be healthier. This result corresponds with Rainer et al. (2013) ${ }^{[13]}$ 's research that consumers have different perceptions on organic and local food. Some consumers think organic food is healthier compared to the local food. The experiment also documented people's agreeableness on how much they are willing to pay for the price premium of organic and local food. The mean for willingness to pay for the price premium for organic food is 3.68, which is lower than the both participants' opinions on organic food and organic food being healthier. Safdar et al. (2015) ${ }^{[14]^{\prime}}$ s research explains this observation. Their research indicates that a consumer's income level is an important determinant of people's willingness to pay for organic food. Participants have different household income levels, so their willingness to pay for the organic food is different. Even though their opinion on organic food is very positive, other crucial factors can affect their purchase decision and would not pay higher for the organic food. Participants' opinion on paying the price premium for local food is less positive compared to participants' opinions on local food and local food being healthier. The reason for this observation is similar to the reason for the willingness to pay for organic food, that participant's income level can influence their purchase decision.

\subsection{Rating on taste}

Slice A and slice organic are from the same organic apple, but the only difference here is labeling. Slice B and Slice local are from the same local apple. The experiment was based on the assumption that slice organic would get a higher rate than slice A, even if they are from the same apple. The rating mean for slice A is 3.175. The rating for slice organic is 4 , which is higher than slice A. The result corresponds with the experiment's assumption. The standard deviation for slice organic is higher than that of slice A. The research from Bernard and $\operatorname{Liu}(2017)^{[10]}$ can provide insight to explain the situation that people have different opinions on organic food, and their opinion can have a positive or negative influence on their taste. The same result can also be observed from slice B and slice local. Moreover, the taste rat- 
ing for slice $\mathrm{C}$ is higher than both slice $\mathrm{A}$ and slice $\mathrm{B}$, but it is lower than the slice local and organic. This observation provides evidence that people's taste perception is biased and can be influenced by the opinions toward the subject.

\subsection{Factor analysis}

The experiment adapts factor analysis to interpret participants' different opinions regarding organic and local food influence participants' taste perception. The experiment uses factor analysis with varimax rotation to develop the factors. Firstly, the KMO (Kaiser-Meyer-Olkin Measure of Sampling Adequacy) has been used to test how much of the variance in variables can be caused by underlying factors. The result shows that overall $83.73 \%$ of the variance in those six variables can be explained by underlying factors.

After doing the KMO test, the result shows three factors after rotating the result. The price premium supporters identify participants who think they should pay more for the organic and local food. The health supporters identify participants who think organic or local food can provide additional health benefits to their body. Organic and local supporters of the market participiants hold overall positive opinion to organic and local food.

\subsection{Regression model}

The participant's background information and factors listed above are used in the one-limit Tobit regression model. The data needed to be analyzed by the Tobit model because the difference in rating, which is the dependent variable here, is potentially censored from below. The dependent variable has a lower boundary of 0 , and half of the observations hit this limit. The mean of the difference in rating is lower than the mean of positive difference in rating, which would cause bias, and the true value cannot be observed when both of the ratings are at an extreme. This model is proposed to help explain the relationship between the dependent variable and independent variables.

ratediff $=\beta_{0}+\beta_{1}$ female $+\beta_{2}$ age $+\beta_{3}$ college $+\beta_{4}$ income $+\beta_{5}$ orglocsup $+\beta_{6}$ healthsup $+\beta_{7}$ premiumsup $+\varepsilon$

The result shows the coefficient result of Tobit regression for the taste rating difference between labeled organic apple slice and unlabeled organic apple slice. There are two significant variables in this model. The health benefits supporter factor is significant. It means when holding everything else constant, the participants with a positive opinion toward organic and local food can have benefits for their health will have 1.418 higher rating differences compared to participants who do not have a positive opinion. The result is expected to be this way because according to Nadricka el ta. $(2020)^{[15]}$, People tend to think organic food is healthier and tastier compared to conventional food. The price premium factor is also significant. It means when holding everything else constant, the participants who are willing to pay higher for organic and local food will have a 2.0285 higher rating difference compared to participants who do not want to pay the premium. The result corresponds with the expectation that the price has a positive influence on the taste perception.

\section{Survey on apple shopping}

\subsection{Data description}

A survey was conducted among 74 participants. The participants of the survey were people living in the US. The participants for the experiment were different from the participants of the survey. The survey was conducted in order to analyze and check a relationship between the retail price of apples and people's willingness to pay to check if there is a relationship between people's shopping patterns and retail prices. This survey was mainly conducted to analyze people's willingness to pay for the apples they buy, whether to be organic or inorganic, from stores or on-line. Also, the survey was conducted to develop key insights about how people's behavior while shopping can determine the pricing strategies for retail stores. Hence, this survey is really essential for big retail companies looking at marketing and pricing models that are based on consumer trends and behavior.

\subsection{Data analysis}

Female, Online, Organic Produce, Organic_Produce, Local_Produce, Organic_Pay, Buy_Quantity and Lo- 
cal_Pay are dummy variables. MaxPriceDiffO is a variable calculated from the absolute value of the difference between maximum price people are willing to pay(Organic and Inorganic) and National Average Retail Price for Organic and Inorganic apples. MaxPriceDiffL is a variable calculated from the absolute value of difference between maximum price people are willing to pay (Local and Imported) and National Average Retail price. Max_will_pay is the variable including values of maximum price people are willing to pay.

The main key insights that can be developed from the Descriptive Summary of the survey is that the mean of Organic_Produce that is 0.878 is less than the mean of Local_Produce which is 0.973 . This indicated that consumers are in support of local produce more as compared to organic produce. However, the mean of Organic_Pay is 0.5 and the mean of Local_Pay is 0.432 . This indicates that although consumers are in support of local produce as compared to organic apples, they are willing to pay more for organic apples in comparison with local apples. This can also be verified from the mean of MaxPriceDiffO and MaxPriceDiffL which are 1.392 and 0.879 that the price difference is more between max price people are willing to pay for organic apples than the average retail price as compared to price difference between maximum price people are willing to pay for local apples and the average retail price. Another verification is that the mean of organic is lesser than the mean of local with values 0.378 and 0.824 respectively.

\subsection{Regression model and results}

The results generated from the survey are analysed using the Logistic regression model. There are two Logistic models generated. First model considers Oraginc_Pay as a dependent variable. This variable is a binary variable that indicates whether people are willing to pay higher for organic produce or not. Similarly, for the second Logistic model, Local_Pay was taken as a dependent variable with value 1 if consumers are willing to pay higher for local apples and value 0 if otherwise.

Average price was calculated from Minimum Price that people are willing to pay and Maximum price people are willing to pay. AverageRetailPriceDiff is the difference between the sample Average Price for one apple and National Average Retail Price for one apple. MaxPrice DiffDiffO is a variable calculated from the absolute value of the difference between maximum price people are willing to pay (Organic and Inorganic) and National Average Retail Price for Organic and Inorganic apples. Logistic Regression was conducted both for Organic_pay and Local_Pay.

For the first Logistic Regression, Organic_Pay was considered as a dependent variable. The equation for the Logistic Model is as follows:

$$
\begin{array}{r}
\text { Pr(Organic_Pay }=1 \mid \text { Female, Online, Organic, MaxPriceDiffO) } \\
=\beta_{0}+\beta_{1} \text { Female }+\beta_{2} \text { Online }+\beta_{3} \text { Organic }+\beta_{4} \text { MaxPriceDiffo }+\varepsilon
\end{array}
$$

The statistically significant variables are Female, Organic and MaxPriceDiffO. This provides the key insights that the probability of agreeing for willing to pay more for Organic increases with increase in shopping for organic apples and with increase in the price differences between average retail price in the market and the maximum price that people are willing to pay. In other words, the probability of willing to pay more increases with Price difference between maximum price willing to pay for Organic Apples and Average Price. Another interesting insight found was that females are probably willing to pay more for organic apples.

For the second Logistic Regression, Local_Pay was considered as a dependent variable.The equation for the model is as follows:

$$
\begin{gathered}
\text { Pr }(\text { Local_Pay }=1 \mid \text { Female,Online,_Local,MaxPriceDiffL,_AvgRetailPriceDiff }) \\
=\beta_{0}+\beta_{1} \text { Female }+\beta_{2} \text { Online }+\beta_{3} \text { Organic }+\beta_{4} \text { MaxPriceDiffO }+\beta_{5} \text { AvgRetailPriceDiff }+\varepsilon
\end{gathered}
$$

MaxPriceDiffL is the absolute value of difference between maximum price that people are willing to pay and National Average Price for Local and Imported Apples. The statistically significant variables are MaxPriceDiffL and AverageRetailPriceDiff. They key insight developed here is that the probability of willing to pay more increases with price difference between maximum price willing to pay for Local Apples and Average Price.

\section{Linear regression of retail price on demand side}




\subsection{Data description and result}

Another Linear regression model was developed. This model was developed to predict a relation between retail price on farm price and on-highway diesel costs. The variety taken for retail prices was Red Delicious. This is because Red Delicious has been the most popular Apple variety in the US since more than 20 years. Data for retail prices and farm prices of Red Delicious Apples was taken for the years from 1994-2019. Data for on-highway diesel costs for the trucks used for transportation was also collected for those particular years. For the regression retail price was taken as a dependent variable. The equation for the Linear regression model is:

$$
\text { RetailPrice }=\beta_{0}+\beta_{1} \text { Farmprice }+\beta_{2} \text { FuelPrice }+\epsilon
$$

This model predicts that Retail Price is also dependent on Farm Price and Fuel Price. Retail price is positively related to Farm and Fuel price. The statistically significant variables are Farm Price and Fuel Price.

\section{Discussion}

From the results listed above, it is reasonable to conclude that consumers' opinions can alter their taste perception. People's opinion is important when they make purchase decisions. When they think this specific type of apple tastes better, they would be more likely to purchase this type of apple. Retailers can develop marketing strategies specifically toward target consumers, to earn higher profit margins. From the taste experiment, it is also obvious that people perceive labels in a very different way. People with a certain income level would pay the price premium to organic apple, local apple, or non-genetically modified apple, and they perceive the apple price to be more inelastic. Retailers can shift their focus to the organic apple sector or local apple sector when apple prices fluctuate drastically.

It can be concluded from the survey that people are in support of Local Apples as compared to Organic Apples but are willing to pay more for Organic Apples than Local Apples. Another conclusion that can be drawn is that this survey indicates that there is a huge profit margin for retailers as consumers are willing to pay more for organic apples than the average market price for the apples. Also, females are willing to pay more for organic apples as compared to males. Hence this survey provides an opportunity for retailers to develop strategies to focus on targeted consumers with separate approaches.

There are some limitations to this research. Firstly, the number of participants in both surveys and experiments is 74 and 40, respectively. The numbers are small, and hence external validity might not be strong.

For the survey, some of the variables like Average price people are willing to pay omitted due to multi-collinearity. Also, variables like Buy_Quantity and Store Section, which provide relevant information about consumer shopping behavior and preferences like whether the pick apples individually or buy the whole packets, whether they look at the organic section first or the inorganic section first. These variables provide useful data about consumer habits, but they were not useful in the models. Hence they provide good scope for further analysis.

The trend in Apple marketing and supply is shifting towards to add more values and provide better products and services to the customers. These trends are useful in determining the ability to handle the growing competition. Harvesting, supplying and marketing fresh apples is becoming more complex, more expensive, and has started involving more risks. The firms skilled at recognising emerging opportunities and managing their organizations accordingly will continue to make profits. Hence, the research conducted here includes marketing strategies and opportunities to make use of price fluctuations to earn higher profit margins.

\section{References}

1. Freebairn JW. Farm and Retail Food Prices. Review of Marketing and Agricultural Economics 1984; 52: 71-90.

2. Thompson GD, Lyon CC. Marketing order impacts on farm-retail price spreads: The Suspension of prorates on California-Arizona Navel Oranges. American Journal of Agricultural Economics 1989; 71(3): 647-660. doi: $10.2307 / 1242020$.

3. Plattner K, Perez A, Thornsbury S. Evolving U.S. fruit markets and seasonal grower price patterns. Economic Research Service 2014;

4. Ho ST, Ifft JE, Rickard BJ, et al. Alternative strategies to manage weather risk in perennial fruit crop production. Agricultural and Resource Economics Review 2018; 47(3): 452-476. 
5. Volpe R, Roeger E, Leibtag E. How transportation costs affect fresh fruit and vegetable prices. Economic Research Report 2013.

6. Richard V. Impact of oil prices on produce prices depends on route and mode of transportation. Amber Waves: The Economics of Food, Farming, Natural Resources, \& Rural America 2016; 1-3.

7. Karipidis PI, Galanopoulos K. Food market value analysis: Product quality improvement, product origin protection and timing decisions in apple market. Agricultural Economics Review 2000; 1(1): 169-176.

8. Khan J, Shah SA, Saddozai KN, et al. A hedonic price analysis of consumer's preferences and willingness to pay for quality attributes of apple. Sarhad Journal of Agriculture 2019; 34(4).

9. Weibel FP, Kruczynska D, Konopacka D. Consumer preference of apple cultivars suited for organic production and which factors influence the buying decision. Acta Horticulturae 2012; (933): 645-652.

10. Bernard JC, Liu Y. Are beliefs stronger than taste? A field experiment on organic and local apples. Food Quality and Preference 2017; 61: 55-62.

11. Jo J, Lusk JL. If it's healthy, it’s tasty and expensive: Effects of nutritional labels on price and taste expectations. Food Quality and Preference 2018; 68: 332-341.

12. Wolfe E, Popp M, Bazzani C, et al. Consumers' willingness to pay for edamame with a genetically modified label. Agribusiness 2018; 34(2): 283-299.

13. Haas R, Sterns J, Meixner O, Nyob DI, et al. Do us consumers’ perceive local and organic food differently? An analysis based on means-End chain analysis and word association. International Journal on Food System Dynamics 2013; 4(3): 214-226.

14. Muhammad S, Fathelrahman E, Ullah RUT. Factors affecting consumers' willingness to pay for certififed organic food products in United Arab Emirates. Journal of Food Distribution Research 2015; 46(1).

15. Nadricka K, Millet K, Verlegh PWJ. When organic products are tasty: Taste inferences from an Organic = Healthy Association. Food Quality and Preference 2020; 83. 